Int. J. Electrochem. Sci., 13 (2018) $58-70$

\title{
The Fabrication of in Situ Triton X-100 on Multi-Walled Carbon Nanotubes Modified Gold Electrode for Sensitive Determination of Caffeine
}

\author{
Kanit Mukdasai ${ }^{1}$, Siriboon Mukdasai ${ }^{2, *}$ \\ ${ }^{1}$ Department of Mathematics, Faculty of Science, Khon Kaen University, Khon Kaen 40002, Thailand \\ ${ }^{2}$ Materials Chemistry Research Center and Center of Excellence for Innovation in Chemistry, \\ Department of Chemistry, Faculty of Science, Khon Kaen University, Khon Kaen 40002, Thailand \\ E-mail: sirimuk@kku.ac.th
}

doi: $10.20964 / 2018.01 .39$

Received: 6 September 2017 / Accepted: 28 October 2017 / Online Published: 1 December 2017

\begin{abstract}
A new type of modified electrode based on a multi-walled carbon nanotubes (MWCNTs) was fabricated onto gold electrode $(\mathrm{Au})$ and used to determine the electrochemical behavior of caffeine

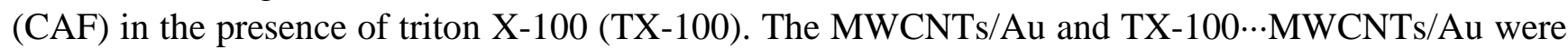

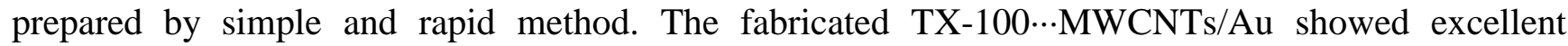
electrochemical catalytic activities towards CAF with bare AuE by differential pulse voltammetry (DPV) and offer anodic peak at $1.45 \mathrm{~V}$. The oxidation potential of CAF at the TX-100 $\cdots \mathrm{MWCNTs} / \mathrm{Au}$ shifted negatively and the anodic peak currents were greater than MWCNTs/Au and bare Au. In the

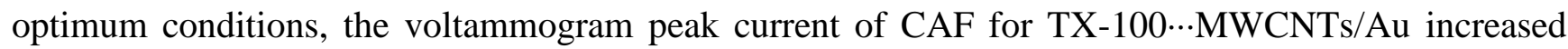
linearly and the linear range was from 0.58 to $11.50 \mu \mathrm{M}$. The limits of detection $(\mathrm{S} / \mathrm{N}=3)$ for CAF was $0.08 \mu \mathrm{M}$. The recoveries of the CAF from spiked tea samples were 83.9-100.3\%. The proposed method has high potential for use as a sensitive sensor for detection of CAF in beverage samples.
\end{abstract}

Keywords: Caffeine; Multi-walled carbon nanotube; Differential Pulse Voltammetry; Triton X-100

\section{$\underline{\text { FULL TEXT }}$}

(C) 2018 The Authors. Published by ESG (www.electrochemsci.org). This article is an open access article distributed under the terms and conditions of the Creative Commons Attribution license (http://creativecommons.org/licenses/by/4.0/). 